\title{
Disease modifying therapies in multiple sclerosis
}

\section{Report of the Therapeutics and Technology Assessment Subcommittee of the American Academy of Neurology and the MS Council for Clinical Practice Guidelines}

\author{
D.S. Goodin, MD; E.M. Frohman, MD; G.P. Garmany, Jr., MD; J. Halper, MSN, ANP, FAAN; \\ W.H. Likosky, MD; F.D. Lublin, MD; D.H. Silberberg, MD; W.H. Stuart, MD; and S. van den Noort, MD
}

Overview. Clinical types of MS. MS is a chronic recurrent inflammatory disorder of the CNS. The disease results in injury to the myelin sheaths, the oligodendrocytes, and, to a lesser extent, the axons and nerve cells themselves. ${ }^{1-5}$ The symptoms of MS vary, depending in part on the location of plaques within the CNS. Common symptoms include sensory disturbances in the limbs, optic nerve dysfunction, pyramidal tract dysfunction, bladder or bowel dysfunction, sexual dysfunction, ataxia, and diplopia. ${ }^{5}$ Four different clinical courses of MS have been defined. ${ }^{6}$ The first, relapsing-remitting MS (RRMS), is characterized by self-limited attacks of neurologic dysfunction. These attacks develop acutely, evolving over days to weeks. Over the next several weeks to months, most patients experience a recovery of function that is often (but not always) complete. Between attacks the patient is neurologically and symptomatically stable. The second clinical course, secondary progressive MS (SPMS), begins as RRMS, but at some point the attack rate is reduced and the course becomes characterized by a steady deterioration in function unrelated to acute attacks. The third clinical type, primary progressive MS (PPMS), is characterized by a steady decline in function from the beginning without acute attacks. The fourth type,

Additional material related to this article can be found on the Neurology Web site. Go to www.neurology.org and scroll down the Table of Contents for the January 22 issue to find the title link for this article. progressive-relapsing MS (PRMS), also begins with a progressive course although these patients also experience occasional attacks.

Outcome measures in MS clinical trials. Evaluation of the relative effectiveness of different therapies requires consideration of which outcome measure or measures are relevant to the goals of therapy. Clearly, the most important therapeutic aim of any disease-modifying treatment of MS is to prevent or postpone long-term disability. However, long-term disability in MS often evolves slowly over many years. ${ }^{1-3}$ Clinical trials, by contrast, study patients for only short periods of time (2 or 3 years) and, therefore, use only short-term outcome measures to assess efficacy. As a result, it is important to validate any short-term measure by its correlation with the actual patient outcome many years later. For a discussion of these issues, interested readers should consult the full-length assessment on the Neurology Web site at www.neurology.org.

Scope of this guideline. The purpose of this assessment is to consider the clinical utility of these disease-modifying agents including the anti-inflammatory, immunomodulatory, and immunosuppressive treatments that are currently available. Symptomatic and reparative therapies will not be considered.

Before considering the evidence from individual

Approved by the TTA Subcommittee August 3, 2001. Approved by the Practice Committee August 4, 2001. Approved by the AAN Board of Directors October $20,2001$.

Address correspondence and reprint requests to the American Academy of Neurology, 1080 Montreal Ave., St. Paul, MN 55116. 
trials, however, a few statistical and interpretational points are worth bearing in mind. First, although a $p$ value of 0.05 is commonly taken as evidence of a therapeutic benefit to treatment, there is concern that this may be too liberal a standard. For example, the Type I error rate (i.e., the so-called $\alpha$-error) reflects the likelihood of concluding incorrectly that a useless treatment is of value. Surprisingly, however, for an experimental observation with a $p$ value of 0.05 , the calculated (i.e., theoretically expected) minimum Type I error rate, for a two-tailed comparison, is actually $13 \% .^{7-10}$ For a one-tailed comparison, this minimum Type I error rate is actually $21 \% .^{7-10}$ Thus, if the aim is to reduce the Type I error rate to the nominal value of $5 \%$ for statistical significance (for a single comparison), using this type of analysis, the observed $p$ value would need to be $\leq 0.01 .^{7-10}$ Consequently, when evaluating the results from a particular trial, statistical observations between $p=$ 0.01 and $p=0.05$ should be regarded as marginal. This is especially true when the study under consideration reports multiple between-group statistical comparisons, because multiple comparisons markedly inflate the actual Type I error rate and require a much more stringent statistical adjustment. ${ }^{11-15}$ There is also concern about the Type II error rate of clinical trials (i.e., the so-called $\beta$ error), which reflects the likelihood of concluding incorrectly that a useful treatment is of no value. ${ }^{16}$ For example, one recent trial ${ }^{17}$ found that after 2 years of treatment, sustained disability progression was nonsignificantly reduced by $12 \%$. Clearly, such a result cannot be used to reject a true $12 \%$ reduction in this measure, and, in fact, this nonsignificant observation is still compatible with an even more robust treatment effect. ${ }^{16}$ The issue is the statistical power (i.e., 1- $\beta$ ) of the clinical trial to detect group differences and this, in turn, is related to the number of subjects studied. ${ }^{16}$ In this particular trial, ${ }^{17}$ the number of subjects studied (i.e., 251) provided insufficient power to detect a $12 \%$ change on this outcome. If a much larger number of subjects had been entered into the trial, and if the same magnitude and variability of the treatment effect had been obtained, this change would have been statistically significant. As a consequence of such difficulties, it is important to recognize that negative results from small clinical trials generally provide little assurance that a true treatment effect has not been missed. Second, because it is uncertain which outcome measures correlate best with future function, clinical trials that use a combination of outcome measures, including both clinical and confirmatory MRI measures, should be judged as stronger evidence than those that rely on only a single measure, especially when that measure is a subjective clinical score. Third, it is important to recognize that both the statistical significance of a finding and the magnitude of the treatment effect (i.e., the effect-size) provide important complementary information about the quality of the evidence. The statistical significance relates to the believability of a result, whereas the effect size relates to its clinical importance. Trials with large effects of marginal significance and trials with significant effects of marginal importance should both be judged as providing equivocal evidence. Fourth, it should be noted that treatments aimed at limiting future CNS injury would not be expected to cause an already disabled patient to improve dramatically, even though some patients may experience some clinical improvement based on intrinsic self-repair mechanisms. Consequently, reports of substantial improvement following the use of such agents should be viewed with caution.

A synopsis of the conclusions and recommendations for all the treatments considered is provided in the Summary. The actual analysis of the evidence (table), however, is provided here only for the immunomodulatory treatments. Readers interested in the analysis of the evidence for other therapies should consult the full-length assessment on the Neurology Web site at www.neurology.org.

Analysis of the evidence. Immunomodulatory treatments. Interferon beta. Clinical trial results. The multicenter study of IFN $\beta$-1b (Betaseron; Berlex Laboratories, Montville, NJ) in RRMS ${ }^{18-20}$ was randomized, double-blind, and placebo-controlled (Class I evidence). It included 372 patients with RRMS who had scores on the extended disability status scale (EDSS) $\leq 5.5$ and who had experienced at least two attacks in the prior 2 years. Patients were randomized to receive placebo, low-dosage (1.6 million of International Units [MIU]; $50 \mu \mathrm{g}$ ), or high-dosage (8 MIU; $250 \mu \mathrm{g}$ ) IFN $\beta-1 \mathrm{~b}$ subcutaneously (SC) every other day for 2 years. After 2 years, compared with placebo, treatment with high-dosage IFN $\beta-1 b$ reduced the clinical relapse rate $(-34 \% ; p<0.0001)$, which was the primary endpoint of the study. In addition, the MRI attack rate as measured by median number of T2 active lesions $(-83 \% ; p<0.009)$ and the median volume of MRI T2 disease burden $(-17.3 \% ; p=0.001)$ were reduced in the IFN $\beta-1 b$ arm compared with placebo-treated patients. The high dosage also resulted in a reduction in the confirmed 1-point EDSS progression rate, but this was not statistically significant $(-29 \% ; p=0.16)$. This trial, however, did report a reduction in the unconfirmed 1-point EDSS worsening over 3 years of study $(-31 \% ; p=0.043)$.

In summary, this trial provides (Class I) evidence that IFN $\beta$ reduces the relapse rate (measured either clinically or by MRI) in patients with RRMS. The effect of treatment on measures of disease severity (i.e., MRI disease burden and disability progression) is less consistent. There was a robust effect of treatment on the MRI disease burden but no statistically significant effect on the measure of confirmed 1-point EDSS progression.

The IFN $\beta-1 a$ (Avonex; Biogen, Cambridge, MA) trial $^{21-23}$ also was multicenter, randomized, and placebo-controlled (Class I evidence). It included 301 


\begin{tabular}{|c|c|c|}
\hline Rating of recommendation & $\begin{array}{l}\text { Translation of evidence to } \\
\text { recommendations }\end{array}$ & Rating of therapeutic article \\
\hline $\begin{array}{l}\text { A-Established as effective, } \\
\text { ineffective, or harmful for the } \\
\text { given condition in the specified } \\
\text { population. }\end{array}$ & $\begin{array}{l}\text { Level A rating requires at least } \\
\text { one convincing Class I study or } \\
\text { at least two consistent, } \\
\text { convincing Class II studies. }\end{array}$ & $\begin{array}{l}\text { Class I: Prospective, randomized, controlled clinical trial } \\
\text { with masked outcome assessment, in a representative } \\
\text { population. The following are required: } \\
\text { a. primary outcome(s) is/are clearly defined, } \\
\text { b. exclusion/inclusion criteria are clearly defined, } \\
\text { c. adequate accounting for dropouts and crossovers } \\
\text { with numbers sufficiently low to have minimal } \\
\text { potential for bias, } \\
\text { d. relevant baseline characteristics are presented and } \\
\text { substantially equivalent among treatment groups } \\
\text { or there is appropriate statistical adjustment for } \\
\text { differences. }\end{array}$ \\
\hline $\begin{array}{l}\text { B-Probably effective, ineffective, } \\
\text { or harmful for the given } \\
\text { condition in the specified } \\
\text { population. }\end{array}$ & $\begin{array}{l}\text { Level B rating requires at least } \\
\text { one convincing Class II study or } \\
\text { at least three consistent Class } \\
\text { III studies. }\end{array}$ & $\begin{array}{l}\text { Class II: Prospective matched group cohort study in a } \\
\text { representative population with masked outcome } \\
\text { assessment that meets a-d above or a RCT in a } \\
\text { representative population that lacks one criteria a-d. }\end{array}$ \\
\hline $\begin{array}{l}\text { C-Possibly effective, ineffective, } \\
\text { or harmful for the given } \\
\text { condition in the specified } \\
\text { population. }\end{array}$ & $\begin{array}{l}\text { Level C rating requires at least } \\
\text { two convincing and consistent } \\
\text { Class III studies. }\end{array}$ & $\begin{array}{l}\text { Class III: All other controlled trials (including well- } \\
\text { defined natural history controls or patients serving as } \\
\text { own controls) in a representative population, where } \\
\text { outcome assessment is independent of patient } \\
\text { treatment. }\end{array}$ \\
\hline $\begin{array}{l}\text { U-Data inadequate or conflicting. } \\
\text { Given current knowledge, } \\
\text { treatment is unproven. }\end{array}$ & & $\begin{array}{l}\text { Class IV: Evidence from uncontrolled studies, case } \\
\text { series, case reports, or expert opinion. }\end{array}$ \\
\hline
\end{tabular}

patients with RRMS who had an EDSS score of 1.03.5, and who had experienced at least two attacks in the 3 years prior to entering the study. Patients were treated either with placebo or IFN $\beta-1 \mathrm{a}, 6 \mathrm{MIU} / \mathrm{wk}$ (30 $\mu \mathrm{g} / \mathrm{wk})$, intramuscularly (IM) for 2 years. This trial was stopped earlier than originally designed, so only $57 \%$ (172 patients) completed the full 2 years on study medication. Compared with placebo, treatment with Avonex for 2 years produced a reduction in the confirmed 1-point EDSS progression rate $(-37 \% ; p=$ 0.02 ), which was the primary endpoint of the trial. In addition, the clinical attack rate $(-18 \% ; p=0.04)$ and the MRI attack rate as measured by the median number of gadolinium enhancing lesions $(-33 \%$; $p=$ 0.05 ) were reduced in the IFN $\beta-1 \mathrm{a}$ arm compared with placebo-treated patients. The total volume of $\mathrm{T} 2$ disease burden seen on MRI also was reduced compared with placebo, but this was not statistically significant $(-6.7 \% ; p=0.36)$. This trial also found that the reduction in attack rate in the first year of therapy $(-9.6 \%$, not significant) was less than the reduction in patients who had completed 2 years of therapy $(-32 \% ; p=0.002)$, suggesting that the full clinical benefits of IFN $\beta$-1a therapy might be delayed for a year or more after the initiation of treatment. ${ }^{21,24,25}$ Nevertheless, the authors provide no statistical evidence of a difference between the 1-year and 2-year data, and, in addition, the other IFN $\beta$ trials in RRMS did not observe such a delay in therapeutic benefit. ${ }^{18-20,24,26,27}$ Most important, however, this subgroup of patients (who had a $32 \%$ reduction in attack rate over 2 years) had a similar reduction in attack rate $(-29 \%)$ at the 1-year mark. ${ }^{25}$
Such an observation indicates that this particular subgroup of patients (i.e., the 2-year completers) is not representative of the study cohort as a whole. As a result of this anticipated bias, the validity of any separate analysis on this subgroup of patients is questionable. A re-analysis of the trial data (for the subgroup of 2-year completers only) using the "brain parenchymal fraction" to measure brain atrophy ${ }^{28}$ showed no statistically significant reduction in brain atrophy after 2 years of treatment $(p=0.30)$. A subgroup analysis did show a reduction of accumulated atrophy in the second year of treatment $(p=$ 0.03). This latter observation, however, was only marginally significant and was the result of a post hoc analysis on a biased subset of the study population, and the reported $p$ value was not adjusted for the three between-group statistical comparisons of brain parenchymal fraction presented in the article's figure. ${ }^{28}$ Therefore, the validity of this observation is uncertain.

In summary, this trial provides (Class I) evidence that IFN $\beta-1 \mathrm{a}$ reduces the biologic activity of RRMS. Importantly, the results of this trial replicate, in general, the earlier IFN $\beta-1 b$ trial for both clinical and MRI outcomes, although again the effect of treatment on attack rate measures was more consistent than for measures of disease severity. Thus, both clinical and MRI measures of attack rate were similarly improved at 2 years. In addition, there was a reduction in the confirmed 1-point EDSS progression rate, although there was no statistically significant concomitant benefit on either MRI disease burden or brain atrophy during the 2 years of study. 
The IFN $\beta-1 a$ (Rebif; Serono International SA, Geneva, Switzerland) trial ${ }^{26,27}$ was a similarly randomized, multicenter, double-blind, and placebocontrolled study (Class I evidence). A total of 560 patients with RRMS with an EDSS score $\leq 5.0$ were entered. Only patients who had experienced 2 or more relapses in the prior 2 years were included. Patients were treated for 2 years with placebo or IFN $\beta-1 \mathrm{a}$ at dosages of either $22 \mu \mathrm{g}$ (6 MIU) or $44 \mu \mathrm{g}$ (12 MIU) SC three times weekly. After 2 years, there was a significant beneficial effect of treatment with either dose on both clinical and MRI outcome measures. Thus, compared with placebo, treatment with IFN $\beta-1 \mathrm{a}, 132 \mu \mathrm{g} / \mathrm{wk}$ (36 MIU/wk), reduced the clinical attack rate $(-32 \% ; p<0.005)$, which was the primary endpoint of the trial. In addition, the MRI attack rate as measured by median number of $\mathrm{T} 2$ active lesions $(-78 \% ; p<0.0001)$, the volume of white matter disease seen on T2-weighted MRI $(-14.7 \% ; p<0.0001)$, and the confirmed 1-point EDSS progression rate $(-30 \% ; p<0.05)$ also were reduced in the IFN $\beta-1 \mathrm{a}$ arm compared with placebo.

In summary, this trial provides (Class I) evidence that IFN $\beta-1$ a reduces the biologic activity of RRMS. As in other IFN $\beta$ trials, this trial demonstrated a benefit to treatment on both clinical and MRI measures of attack rate. Also, this was the first trial of IFN $\beta$ in RRMS to show both a reduction in the confirmed 1-point EDSS progression and a highly significant reduction in the $\mathrm{T} 2$ disease burden.

The IFN $\beta-1 b$ (Betaferon; Schering AG, Berlin, Germany) trial in SPMS $^{29}$ was a randomized, placebo-controlled, double-blinded study conducted among 32 European centers (Class I evidence). Included were 718 patients with an EDSS of 3.0-6.5. Patients had to have either two relapses or more than a 1.0 point increase in EDSS in the prior 2 years. Those included were randomized to receive either placebo or IFN $\beta-1 b, 250 \mu \mathrm{g}$ (8 MIU) SC, every other day for up to 3 years. Compared with treatment with placebo, treatment with $28 \mathrm{MIU} / \mathrm{wk}$ Betaferon reduced the confirmed 1-point EDSS progression rate $(-22 \% ; p=0.0008)$, the primary endpoint of the study. In addition, the clinical attack rate $(-31 \% ; p=0.0002)$, the MRI attack rate $(-78 \%$; $p=0.0008$ ), and the volume of white matter disease seen on MRI $(-13 \% ; p=0.0001)$ all were significantly reduced in the IFN $\beta-1 b$ arm compared with placebo. This study also demonstrated that treatment with IFN $\beta-1 b$ reduced the likelihood of becoming wheelchair bound during the study $(-33 \% ; p=$ 0.01 ). After dividing patients into those who had experienced clinical attacks in the 2 years before entering the study and those who only experienced steady clinical deterioration, the benefit of treatment was comparable in both subgroups. After dividing patients into those who did and those who did not experience attacks during the trial, the benefit of treatment was again found to be similar in the two subgroups. After dividing patients into three groups based on their baseline EDSS scores (Group $1=$
3.0-3.5; Group $2=4.0-5.5$; and Group $3=6.0-6.5$ ), IFN $\beta-1 \mathrm{~b}$ was found to be similarly beneficial in all three groups. However, when the full 3-year data are analyzed, the benefit of treatment in patients with an EDSS $\geq 6.0$ is not apparent.

In summary, this trial provides (Class I) evidence that treatment with IFN $\beta-1 b$ favorably impacts both clinical and MRI outcomes for attack rate and disease severity in patients with SPMS.

The results of another recently completed (Class I) trial of IFN $\beta-1 b$ (Betaseron) in SPMS also has been reported in preliminary form..$^{30}$ This trial failed to find a statistically significant reduction in the confirmed 1-point EDSS progression rate (the primary endpoint of the trial), although it did report significant reductions in the clinical attack rate, the MRI attack rate, and the volume of white matter disease found on T2-weighted MRI. Publication of the final results from this trial is pending. The reason for the apparently discrepant findings between these two trials of IFN $\beta-1 b$ is not clear. Some observers have noted that the North American cohort of patients had significantly fewer attacks than their European counterparts, and that perhaps IFN $\beta$ is most effective in the relapsing phase of the illness. At the moment, however, such a notion is speculative.

The recently published trial of IFN $\beta$-1a (Rebif) in SPMS $^{31,32}$ also failed to find a statistically significant reduction in the confirmed 1-point EDSS progression rate (the primary endpoint of the trial). Like the IFNb-1b (Betaseron) trial, however, this trial also found significant reductions in the clinical attack rate, the MRI attack rate, and the volume of white matter disease found on T2-weighted MRI. Also, when the results of this trial were reanalyzed by separating patients into those with and those without attacks, a benefit to treatment on the confirmed 1 -point EDSS progression rate was noted ( $p=0.027)$ in patients with relapses. The validity of such a reanalysis of the data is clearly open to question, but nevertheless might be taken as weak support for the speculation (noted above) that IFN $\beta$ is more effective in patients with SPMS who continue to experience relapses.

Another recent (Class I) study of IFN $\beta-1 a$ (Avonex) in the treatment of SPMS has been reported in preliminary form. ${ }^{33}$ Using the MS functional composite as the primary outcome, this trial found that, compared with placebo, treatment with IFN $\beta-1 \mathrm{a}, 60 \mu \mathrm{g} / \mathrm{wk}$, IM was beneficial over a 2 -year period $(p=0.03)$. This study, however, did not find any concomitant benefit on the outcome of confirmed 1-point EDSS progression. Moreover, the benefit seen on the MS functional composite outcome was due primarily to the results from the Nine-Hole Peg Test portion of the composite score. The reported benefit of therapy in this trial, therefore, is of uncertain reliability.

Two recently completed trials of IFN $\beta-1 a$ (Avonex and Rebif) in patients at high risk of developing MS have shown that early treatment significantly slows 
the subsequent rate of conversion to clinically definite MS (CDMS). ${ }^{34,35}$ The IFN $\beta-1 \mathrm{a}$ (Avonex) trial $^{34}$ was a multicenter, randomized, placebo-controlled trial involving 383 patients who were followed for up to 3 years (Class I evidence). Patients needed to have just experienced their first clinically isolated (monosymptomatic) CNS event consisting of an optic neuritis, a spinal cord syndrome, or a brainstem/ cerebellar syndrome. Patients also had to have an abnormal brain MRI defined as two or more clinically silent lesions $(\geq 3 \mathrm{~mm}$ ) on T2-weighted MRI scans, at least one of which needed to be ovoid in appearance or periventricular in location. Patients initially were treated with intravenous methylprednisolone, $1 \mathrm{~g} / \mathrm{d}$ for 3 days, followed by a course of oral prednisone, $1 \mathrm{mg} / \mathrm{kg} / \mathrm{d}$ for 15 days. Patients subsequently received either IFN $\beta-1 \mathrm{a}(30 \mu \mathrm{g} / \mathrm{wk}$, IM) or placebo throughout the study. Using a Cox proportional hazard model, the relative risk of developing CDMS in the treated group was $0.56(p=0.002)$, indicating a $44 \%$ decrease in the rate of conversion to MS after administration of IFN $\beta-1 \mathrm{a}$, which was the primary endpoint of the trial. MRI measures also demonstrated a robust treatment effect. Thus, at 18 months, the number of new lesions $(-57 \% ; p<$ $0.0001)$, the percentage change in the T2 lesion volume $(-14 \% ; p=0.0004)$, and the number of enhancing lesions $(-67 \% ; p<0.0001)$ all were reduced using IFN $\beta-1 \mathrm{a}$ when compared with placebo. The IFN $\beta$-1a (Rebif) trial ${ }^{35}$ also was a multicenter randomized trial (Class I evidence) involving 309 patients who had experienced their first clinical episode suggestive of demyelinating disease (either mono- or polysymptomatic) and who were followed for 2 years thereafter. Patients received either IFN $\beta-1 \mathrm{a}(22 \mu \mathrm{g} / \mathrm{wk}, \mathrm{SC})$ or placebo throughout the study. The proportion of patients converting to CDMS was less in the treated group compared with placebo $(-24 \% ; p=0.047)$. In addition, the median number of T2 active lesions seen on MRI also was reduced in the treated compared with placebo patients $(p<0.001)$. The T2 disease burden also was reduced in the treated arm compared with placebo in both year 1 and year 2 of the trial $(p=0.006$ and $p=$ 0.002 , respectively).

These trials, therefore, provide (Class I) evidence that treatment with IFN $\beta$-1a delays the development of CDMS in patients at high risk for this outcome. Such a result is hardly surprising. Indeed, any treatment for RRMS that can delay the time between attacks 2 and 3 or between attacks 3 and 4 (i.e., any treatment that reduces the attack rate) also would be expected to delay the time between attacks 1 and 2. These studies do not, however, provide evidence that the ultimate development of CDMS is prevented by such treatment. Neither do they provide any evidence that early treatment affects longterm disability outcome.

Effects of IFN $\beta$ type, route of administration, and dose on clinical outcome. The total dosage of IFN $\beta$ used in the different clinical trials of both RRMS and
SPMS has varied considerably between studies and it is important to consider the evidence that there may be a dose-response curve in the use of IFN $\beta$ for the management of patients with MS. Because the pharmaceutical companies that manufacture Avonex, Betaseron, and Rebif use slightly different assays to measure IFN $\beta$ activity, the MIU scales reported in the different papers are not directly comparable between publications. Nevertheless, because Avonex and Rebif are both forms of IFN $\beta-1 a$, they can be compared on a microgram for microgram basis. Also, the conversion of IFN $\beta-1 a$ to IFN $\beta-1 b$ doses can be calculated using published data, ${ }^{36}$ with the result that $6 \mathrm{MIU}$ Avonex $(30 \mu \mathrm{g})$ is equivalent to approximately 7-9 MIU Betaseron (220-280 $\mu \mathrm{g})$.

IFN $\beta$ induces the expression of many gene products and interferon-specific markers, including 2 ',5'oligoadenylate synthetase $\left(2^{\prime}, 5^{\prime}\right.$-OAS), neopterin, tryptophan, $\beta_{2}$-microglobulin, and human $\mathrm{Mx}$ protein. ${ }^{37}$ These markers reflect a range of biologic activities of IFN $\beta$, including MHC Class-I gene expression, antiviral and antiproliferative actions, and monocyte activation. These markers have been used as indicators of the biologic activity of IFN $\beta$. The relative dose of the different preparations also can be assessed from another recent publication ${ }^{38}$ in which antiviral protein (MxA) stimulation was studied in the untreated blood from 10 healthy volunteer subjects. In this study, in vitro stimulation of peripheral blood with all three agents (Avonex, Betaseron, and Rebif) resulted in a dose-dependant increase in MxA levels that was roughly equivalent for each agent on a MIU for MIU basis using the published MIU values.

One study ${ }^{39}$ initially suggested that IM administration of IFN $\beta-1$ a caused a substantially greater area under the concentration-time curve for IFN $\beta$ activity in the serum compared with SC administration. By contrast, a different study ${ }^{36}$ compared the effects of IFN $\beta-1 \mathrm{a}$ given SC and IM and IFN $\beta-1 b$ given $\mathrm{SC}$ on neopterin, human $\mathrm{Mx}$ protein, and $2^{\prime}, 5^{\prime}-$ OAS in 75 healthy volunteer subjects. IFN $\beta-1$ a was administered at doses of $1,3,6,9$, and $12 \mathrm{MIU}$ and IFN $\beta-1 b$ at doses of $2,4,8,12$, and 16 MIU; each patient in the study received a single dose. The results showed that the production of all three markers was induced in a dose-dependent manner for both IFN $\beta-1 \mathrm{a}$ and IFN $\beta-1 \mathrm{~b}$. Moreover, this study found no differences in any of these biologic effects between the two types of IFN $\beta$ or between the different routes of administration. Similar results have been found by other investigators. ${ }^{40,41}$ Thus, the balance of the evidence favors the view that the route of IFN $\beta$ administration is not of clinical importance.

The previously cited study ${ }^{38}$ also examined the levels of MxA in the peripheral blood in 237 patients with CDMS after administration of IFN $\beta$. There were 78 patients receiving IFN $\beta-1 b$ (Betaseron) at a dosage of $8 \mathrm{MIU}(250 \mu \mathrm{g})$ every other day; $71 \mathrm{pa}-$ tients receiving IFN $\beta$-1a (Rebif) at a dosage of 6 MIU $(22 \mu \mathrm{g}) \mathrm{SC}$ either weekly or three times weekly; and 
21 patients receiving IFN $\beta-1$ a (Avonex) at a dosage of 6 MIU $(30 \mu \mathrm{g})$ IM once weekly. The level of MxA was $2.29 \mathrm{ng} / 10^{5}$ peripheral blood lymphocytes (PBL) in the Betaseron-treated patients, $1.00 \mathrm{ng} / 10^{5}$ peripheral blood lymphocytes in the Rebif-treated patients, and $0.57 \mathrm{ng} / 10^{5}$ peripheral blood lymphocytes in the Avonex-treated patients. In summary, the results of this trial suggest that increasing the total weekly IFN $\beta$ dose is associated with an increasing biologic effect (Class II evidence). However, whether the measured biologic effect (on MxA levels) is relevant to the effect of IFN $\beta$ on disease activity, cannot be assessed from this trial.

The results of the pivotal clinical trials of IFN $\beta$ in RRMS also suggest a dose-response curve. ${ }^{18-27}$ Thus, in general, when comparing the different findings of these trials, both the magnitude of the reported effects on clinical and MRI outcomes, as well as their statistical significance, seem to be greater with increasing dosages of IFN $\beta$. Nevertheless, because of differences in trial design, differences in the MS populations studied, and the fact that the results were obtained in independent clinical trials, this observation can only be considered as weak (Class III) evidence of a dose response.

The findings from the two placebo-controlled Class I IFN $\beta$ studies that investigated different doses of IFN $\beta$ provide mixed results. ${ }^{18-20,26,27}$ Thus, in the Betaseron trial, ${ }^{18-20}$ treatment with low-dose IFN $\beta-1 b$ (5.6 MIU/wk) was significantly better than placebo $(p<0.01)$ on the measure of clinical attack rate over the first 2 years, although it was significantly less effective on this measure $(p<0.0086)$ than the higher dose of $28 \mathrm{MIU} / \mathrm{wk}$. Trends in favor of the higher dose also were seen on other outcome measures, although no other statistically significant dose effects were noted. In the Rebif trial, ${ }^{22,26}$ both doses were highly effective, although the high-dose arm did better on each clinical and MRI outcome measure than the low-dose (18 MIU/wk) arm. With the exception of the outcome of T2 active lesions ( $p=0.0003$ comparing low dose to high dose), however, there were no statistical differences between the two doses at the 2-year time point. Thus, although based on high-quality (Class I) studies, the evidence in favor of a dose response provided by these trials is only equivocal.

The Rebif trial was continued for an additional 2 years. ${ }^{42}$ Placebo-treated patients during the first 2 years were re-randomized in a double-blind fashion to receive IFN $\beta-1 \mathrm{a}$, either $66 \mu \mathrm{g}$ or $132 \mu \mathrm{g}$ weekly, in divided doses. After 4 years, a dose-response relationship was seen for some clinical and MRI outcomes but not for others. Thus, the high dose was more effective than the low dose $(p<0.05)$ at reducing the relapse rate during years 3 and 4 , prolonging the time to second relapse, and increasing the percentage of relapse free patients. Similarly, treatment with high dose IFN $\beta-1$ a reduced the MRI disease burden and T2 lesion activity $(p<0.001)$ compared with low dose (Class I evidence). By contrast, the high-dose group was not statistically better than the low-dose group on the outcomes of attack rate measured over years 1 to $4(-12 \% ; p=0.069)$, or the time to confirmed 1-point EDSS progression $(+17 \%$; $p=0.33$ ). In addition, an analysis (Class III evidence) of the combined results of the Avonex and Rebif trials suggested that IFN $\beta-1$ a has increasing clinical efficacy (as measured by the clinical attack rate at 1 year) between the doses of 22 and $132 \mu \mathrm{g}$ weekly. ${ }^{24}$ By contrast, the results of the SPECTRIMS trial of IFN $\beta$-1a in SPMS demonstrated no difference between 66 and $132 \mu \mathrm{g}$ weekly with respect to any clinical outcome measure relating to relapse rate. ${ }^{31}$

The results of a multicenter, double-blind, dosecomparison trial of IFN $\beta-1$ a (Avonex) recently has been reported. ${ }^{43}$ This trial included 678 patients with RRMS who received IFN $\beta-1 a$, either $30 \mu \mathrm{g} / \mathrm{wk}$ or 60 $\mu \mathrm{g} / \mathrm{wk}$, IM once weekly for a period of at least 3 years (Class I evidence). There was no difference in outcome between the two dosage groups with respect to EDSS progression, relapse rate, gadolinium (Gd)enhancing lesions, T2 lesion burden, or brain atrophy over the course of the trial. ${ }^{43}$ This trial thus provides Class I evidence that $60 \mu \mathrm{g}$ IFN $\beta$-1a (IM) once weekly provides no additional benefit over 3 years of therapy compared with $30 \mu \mathrm{g}$ (IM) once weekly over the same period.

Recently, the preliminary results of two head-tohead comparison trials of different IFN $\beta$ preparations have been reported. ${ }^{44,45}$ The first ${ }^{44}$ was a 2 -year, open-label, randomized trial of IFN $\beta-1 b$ (Betaseron; $28 \mathrm{MIU} / w k, \mathrm{SC}$ ) compared with IFN $\beta$-1a (Avonex; 30 $\mu \mathrm{g} / \mathrm{wk}, \mathrm{IM})$ in 188 patients with RRMS. Only the data after 1 year of therapy have been presented. This trial found a greater clinical benefit in the higher dose (more frequently administered) IFN $\beta-1 b$ group, both on clinical outcomes (i.e., relapse free status and sustained progression) and on MRI outcomes (i.e., new T2 lesions or Gd-enhancing lesions), compared with the IFN $\beta$-1a group. The evaluating physician, however, was unblinded for clinical outcomes so that the clinical observations from this trial represent only Class III evidence. MRI, by contrast, was assessed blindly so that these observations represent Class I evidence. The second was a randomized, 1-year, open-label trial ${ }^{45}$ comparing high-dose, more frequently administered, IFN $\beta$-1a (Rebif; 132 $\mu \mathrm{g} / \mathrm{wk}$, SC) to low-dose, once weekly, IFN $\beta$-1a (Avonex; $30 \mu \mathrm{g} / \mathrm{wk}, \mathrm{IM}$ ) in 677 patients with RRMS. Both clinical and MRI outcome measures were assessed in a blinded fashion (Class I evidence). Only data after 6 months of therapy and only outcome measures relating to relapse rate have been presented. At 6 months, the high-dose (more frequently administered) IFN $\beta$-treated group was statistically superior to the low-dose group on both clinical and MRI outcome measures related to attack rate. These clinical outcomes included the odds of being attack free, the attack rate, and the time to first exacerbation and steroid use, whereas the MRI outcomes included the odds of not having new $\mathrm{T} 1$ or T2 lesions, 
the total number of new lesions, and the cumulative number of new active lesions. The design of these trials confounds the effect of IFN $\beta$ dose with the effect of the frequency of IFN $\beta$ administration because, in each, both parameters differed between the two treatment arms. Nevertheless, these trials provide (Class I) evidence that either the dose, or the frequency of IFN $\beta$ administration, or both, significantly influence the short-term outcome in patients with RRMS. The final results from both trials currently are not available. Nevertheless, these final results are critically important and it will be necessary to assess whether these apparent short-term advantages to high-dose (more frequent) IFN $\beta$ therapy are sustained over time.

Neutralizing antibodies to IFN $\beta$ The rate of neutralizing antibody (NAb) production is probably less with IFN $\beta$-1a treatment than with IFN $\beta$-1b treatment, and the presence of NAb may be associated with a reduction in clinical effectiveness of IFN $\beta$ treatment. The existing data are, however, ambiguous in this regard, and the clinical utility of measuring $\mathrm{NAb}$ in an individual on IFN $\beta$ therapy is uncertain. Readers interested in discussion of this issue should consult the full-length assessment on the Neurology Web site at www.neurology.org.

Glatiramer acetate. Glatiramer acetate (Copaxone; Teva-Marion Partners, Kansas City, MO) is a random polypeptide made up of four amino acids (L-glutamic acid, L-lysine, L-alanine, and L-tyrosine) in a specific molar ratio $(1.4,3.4,4.2$, and 1.0 , respectively). The mechanism of action is not known but may relate to a number of immunologic effects such as the induction of antigen-specific suppressor $\mathrm{T}$ cells, inhibition of antigen presentation, displacing bound myelin basic protein (MBP), or causing an immune deviation in $\mathrm{CD}^{+} \mathrm{T}$ cells from a $\mathrm{Th}_{1}$ to $\mathrm{Th}_{2}$ phenotype. ${ }^{46-48}$

The results of a large multicenter, randomized, double-blind, placebo-controlled trial of glatiramer acetate $^{17,49}$ initially were reported in 1995 . This trial involved 251 patients with RRMS who had an EDSS score $\leq 5.0$ and who had experienced two or more relapses in the 2 years before entering the study. Patients received either placebo or $20 \mathrm{mg}$ glatiramer acetate SC daily for up to 3 years. This trial found that treatment with glatiramer acetate significantly reduced the clinical attack rate over a 2 -year period $(-29 \% ; p=0.007)$, which was the primary endpoint of the study. It also reduced the confirmed 1-point EDSS progression rate, although this change was not statistically significant $(-12 \%)$. This trial also reported a reduction in the unconfirmed 1-point EDSS worsening over the first 2 years of the study $(-28 \% ; p=0.037)$. Also, in a secondary analysis of data from the extension phase of this trial, ${ }^{23}$ after excluding determinations made during acute attacks, these authors reported a significant reduction in the unconfirmed 1.5 point EDSS progression rate over 3 years in the treated patients compared with control subjects $(-48 \% ; p=0.004)$ using survival analysis methods. This last analysis, however, is of uncertain reliability. This outcome has not been used by other investigators, and, moreover, this particular outcome was arrived at through post hoc exploration of the data; thus, the observation is of uncertain validity. No MRI outcomes were determined as part of this trial. A second short duration European/ Canadian trial, was undertaken to look specifically at MRI measures.50 This was a placebo-controlled trial and involved 249 patients with RRMS who were randomized to receive either placebo or $20 \mathrm{mg}$ glatiramer acetate SC daily for 9 months (Class I evidence). Patients, at entry, had to have an EDSS score of 0-5.0, they had to have experienced at least 1 clinical attack in the previous 2 years, and they had to have a Gd-enhancing lesion on their screening brain MRI. This trial reported that, compared with placebo, the treated group had a reduction in the total number of enhancing lesions $(-35 \% ; p=$ 0.001 ), which was the primary endpoint of the trial. This treatment effect, however, was delayed until 6 months after initiation of treatment. Treated patients also had a reduction in the clinical attack rate $(-33 \% ; p=0.012)$ and a reduction in the median change in T2 burden of disease $(-8.3 \% ; p=0.0011)$ compared with placebo. EDSS change over the course of the trial was minimal and was not different between the treatment and placebo groups. ${ }^{50}$

An earlier pilot trial (Class I) of glatiramer acetate at comparable dosage ${ }^{51}$ also reported a reduction in both the clinical attack rate $(-76 \% ; p<0.001)$ and the confirmed 1-point EDSS progression rate $(-60 \%$; $p=0.05$ ). MRI outcomes were also not assessed in this pilot trial. Another early pilot trial (Class I) of glatiramer acetate in the treatment of chronic progressive MS (including both PPMS and SPMS), reported that treatment with glatiramer acetate $(30 \mathrm{mg} /$ day, SC) reduced the confirmed 1-point EDSS progression rate compared with placebo $(-31 \%)$ although this difference was not statistically significant. ${ }^{52}$

Recently, experience with the extended use of glatiramer acetate over a 6 -year period has been reported. ${ }^{53}$ This trial reports on the experience following 152 patients with RRMS who were initially enrolled in the placebo-controlled randomized trial $^{17,49}$ and who continued to be followed after the breaking of the blind. All patients were on active drug during the follow-up interval and were compared with previously published natural history controls (Class III evidence). The authors reported stabilization of the EDSS score and a marked reduction in the clinical attack rate during follow-up. However, with a $40 \%$ dropout rate (compared with the number who were initially enrolled in the randomized trial), there are concerns that the cohort might be self-selected and, therefore, that the study may be biased in favor of a treatment effect. For example, the annual attack rate during the doubleblind phase in patients who elected to continue on treatment was significantly less $(p<0.001)$ than in patients who decided not to continue $(0.78$ and 1.23 
attacks/y, respectively). Similarly, there was a significant difference $(p=0.003)$ in the percentage of patients who had deteriorated by 1.5 EDSS points during the double-blind phase between those who elected to continue treatment $(40 \%)$ and those who did not (62\%). This cohort represents the longest continuous follow up of a group of treated MS patients for any of the currently available therapies. However, without a concurrent control group for comparison and given the limitations discussed above, it is difficult to know how best to use these data.

Although MRI was not part of the original Phase III clinical trial of glatiramer acetate, ${ }^{17,49}$ the authors recently reported the results of follow-up MRI in 135 of the 147 patients who remained in the long-term open-label follow-up cohort as of January 1999. ${ }^{54}$ In those patients who were initially on placebo, MRI were obtained an average of 4 years after being switched to active drug. By contrast, in those patients on active treatment from the beginning of the trial, MRI were obtained an average of 6.7 years after initiation of glatiramer acetate. Outcome was assessed by comparing different MRI parameters (including a composite MRI measure) between the two groups. The most significant difference reported between groups was a reduction in the percentage of MRI showing Gd enhancement in the patients on glatiramer acetate from the beginning compared with patients originally on placebo $(18.8 \%$ and $36.4 \%$, respectively; $p=0.02$ ). Taken at face value, this observation would suggest that the full benefit of glatiramer acetate therapy in reducing Gd enhancement (a phenomenon that only lasts about 3 months) is delayed for 4 or more years after the initiation of treatment. However, there are several reasons to doubt such an explanation. First, no comparable delay is suggested by the clinical data where the two groups had very similar attack rates within a year of when placebo-treated patients had been switched over to active therapy. ${ }^{53,54}$ Second, no similar delay in the onset of efficacy is suggested by the results of the 9-month MRI trial. ${ }^{50}$ And third, it is very difficult to rationalize how the effect of glatiramer acetate on Gd enhancement could be so markedly delayed. As a result of considerations such as these, it may be more plausible to ascribe this unexpected result to a Type I error; a circumstance that raises similar concerns with respect to the other outcomes reported in this article. ${ }^{54}$

A recent study ${ }^{55}$ reported the results of a prospective 1-year, open-label, nonrandomized trial of once weekly IFN $\beta$-1a (Avonex; $30 \mu \mathrm{g} / \mathrm{wk}$ ), IFN $\beta$-1b (Betaseron; $28 \mathrm{MIU} / \mathrm{wk}$ ), glatiramer acetate (Copaxone; 20 $\mathrm{mg} /$ day), or no treatment in the management of 156 patients with RRMS. These authors reported that, compared with no treatment, clinical relapse rate was reduced in all three active treatment groups, although this reduction was statistically significant only for the IFN $\beta$-1b-treated and glatiramer acetate-treated groups ( $p \leq 0.003$ ), suggesting that these two preparations were more clinically effective than IFN $\beta-1 \mathrm{a}$, at least at the dose and route of administration used in this study. This trial, however, used a nonrandomized design and a nonblinded assessment of outcome; therefore, these data represent only weak (Class III) evidence in support of this conclusion.

\section{Summary}

\section{Glucocorticoids:}

1. On the basis of several and generally consistent Class I and Class II studies, glucocorticoid treatment has been demonstrated to have a short-term benefit on the speed of functional recovery in patients with acute attacks of MS. It is appropriate, therefore, to consider for treatment with glucocorticoids any patient with an acute attack of MS (Type A recommendation).

2. There does not appear, however, to be any long-term functional benefit after the brief use of glucocorticoids in this clinical setting (Type B recommendation).

3. Currently, there is not compelling evidence to indicate that these clinical benefits are influenced by the route of glucocorticoid administration, the particular glucocorticoid prescribed, or the dosage of glucocorticoid, at least at the doses that have been studied to date (Type $\mathrm{C}$ recommendation).

4. On the basis of a single Class II study, it is considered possible that regular pulse glucocorticoids may be useful in the long-term management of patients with RRMS (Type $\mathrm{C}$ recommendation)

\section{Interferon beta:}

1. On the basis of several consistent Class I studies, IFN $\beta$ has been demonstrated to reduce the attack rate (whether measured clinically or by MRI) in patients with MS or with clinically isolated syndromes who are at high risk for developing MS (Type A recommendation). Treatment of MS with IFN $\beta$ produces a beneficial effect on MRI measures of disease severity such as T2 disease burden and probably also slows sustained disability progression (Type B recommendation).

2. As a result, it is appropriate to consider IFN $\beta$ for treatment in any patient who is at high risk for developing CDMS, or who already has either RRMS or SPMS and is still experiencing relapses (Type A recommendation). The effectiveness of IFN $\beta$ in patients with SPMS but without relapses is uncertain (Type U recommendation).

3. It is possible that certain populations of MS patients (e.g., those with more attacks or at earlier disease stages) may be better candidates for therapy than others, although, at the moment, there is insufficient evidence regarding these issues (Type U Recommendation)

4. On the basis of Class I and II studies and several pieces of consistent Class III evidence, it is considered probable that there is a dose-response curve associated with the use of IFN $\beta$ for the treatment of MS (Type B recommendation). It is possible, however, that a portion of this apparent dose-effect instead may be due to differences in the frequency of IFN $\beta$ administration (rather than dose) between studies.

5. On the basis of several Class II studies, the route of administration of IFN $\beta$ is probably not of clinical importance, at least with regard to efficacy (Type $\mathrm{B}$ recommendation). The side-effect profile, however, does differ between routes of administration. There is no known clinical difference between the different types of IFN $\beta$, although this has not been thoroughly studied (Type U recommendation).

6. On the basis of several Class I studies, treatment of patients with MS with IFN $\beta$ is associated with the production of NAb (Type A recommendation). The rate of NAb production, however, is probably less with IFN $\beta-1$ a treatment than with IFN $\beta-1 b$ treatment (Type B recommendation). The biologic effect of NAb is uncertain, although their presence may be associated with a reduction in clinical effectiveness of IFN $\beta$ treatment (Type $\mathrm{C}$ recommendation). Whether there is a difference in immunogenicity between subcutaneous and intra- 
muscular routes of administration is unknown (Type $\mathrm{U}$ recommendation). The clinical utility of measuring NAb in an individual on IFN $\beta$ therapy is uncertain (Type U recommendation).

\section{Glatiramer acetate:}

1. On the basis of Class I evidence, glatiramer acetate has been demonstrated to reduce the attack rate (whether measured clinically or by MRI) in patients with RRMS (Type A recommendation). Treatment with glatiramer acetate produces a beneficial effect on MRI measures of disease severity, such as T2 disease burden, and possibly also slows sustained disability progression in patients with RRMS (Type $\mathrm{C}$ recommendation).

2. As a result, it is appropriate to consider glatiramer acetate for treatment in any patient who has RRMS (Type A recommendation). Although it may be that glatiramer acetate also is helpful in patients with progressive disease, there is no convincing evidence to support this hypothesis (Type U Recommendation).

\section{Cyclophosphamide:}

1. Based on consistent Class I evidence, pulse cyclophosphamide treatment does not seem to alter the course of progressive MS (Type B recommendation).

2. Based on a single Class III study, it is possible that younger patients with progressive MS might derive some benefit from pulse plus booster cyclophosphamide treatment (Type U recommendation).

\section{Methotrexate:}

1. Based on limited and somewhat ambiguous Class I evidence from a single trial, it is considered possible that methotrexate favorably alters the disease course in patients with progressive MS (Type $\mathrm{C}$ recommendation).

\section{Azathioprine:}

1. On the basis of several, but somewhat conflicting, Class I and II studies, it is considered possible that azathioprine reduces the relapse rate in patients with MS (Type C recommendation).

2. Its effect on disability progression has not been demonstrated (Type U recommendation).

\section{Cladribine:}

1. On the basis of consistent Class I evidence, it is concluded that cladribine reduces $\mathrm{Gd}$ enhancement in patients with both relapsing and progressive forms of MS (Type A recommendation).

2. Cladribine treatment does not, however, appear to alter favorably the course of the disease, either in terms of attack rate or disease progression (Type $\mathrm{C}$ recommendation).

\section{Cyclosporine:}

1. Based on this Class I study, it is considered possible that cyclosporine provides some therapeutic benefit in progressive MS (Type C recommendation).

2. However, the frequent occurrence of adverse reactions to treatment, especially nephrotoxicity, together with the small magnitude of the potential benefit, makes the risk/benefit of this therapeutic approach unacceptable (Type B recommendation).

\section{Mitoxantrone:}

1. On the basis of generally consistent Class II and III studies, it is concluded that mitoxantrone probably reduces the attack rate in patients with relapsing forms of MS (Type B recommendation). The potential toxicity of mitoxantrone, however, may outweigh the clinical benefits early in the course of disease.
2. On the basis of several Class II and III observations, it is considered possible that mitoxantrone has a beneficial effect on disease progression in MS, although, at the moment, this clinical benefit has not been established (Type C recommendation).

\section{Intravenous immunoglobulin:}

1. The studies of intravenous immunoglobulin (IVIg), to date, have generally involved small numbers of patients, have lacked complete data on clinical and MRI outcomes, or have used methods that have been questioned. It is, therefore, only possible that IVIg reduces the attack rate in RRMS (Type C recommendation).

2. The current evidence suggests that IVIg is of little benefit with regard to slowing disease progression (Type $\mathrm{C}$ recommendation).

\section{Plasma exchange:}

1. On the basis of consistent Class I, II, and III studies, plasma exchange is of little or no value in the treatment of progressive MS (Type A recommendation).

2. On the basis of a single small Class I study, it is considered possible that plasma exchange may be helpful in the treatment of severe acute episodes of demyelination in previously nondisabled individuals (Type $\mathrm{C}$ recommendation).

\section{Sulfasalazine:}

1. Based on a single Class I study, it is concluded that treatment of MS with sulfasalazine provides no therapeutic benefit in MS (Type B recommendation).

\section{References}

1. Weinshenker BG, Bass B, Rice GPA, et al. The natural history of multiple sclerosis: a geographically based study: I. clinical course and disability. Brain 1989;112:133-146.

2. Weinshenker BG, Bass B, Rice GPA, et al. The natural history of multiple sclerosis: a geographically based study: II. predictive value of the early clinical course. Brain 1989;112:133146.

3. Weinshenker BG. The epidemiology of multiple sclerosis. Neurol Clin 1996;14:291-308.

4. Ferguson B, Matyszak MK, Esiri MM, Perry VH. Axonal damage in acute multiple sclerosis lesions. Brain 1997;120:393399.

5. Compston DA. McAlpine's multiple sclerosis, 3rd ed. New York: Churchill Livingstone, 1998.

6. Lublin FD, Reingold SC. Defining the clinical course of multiple sclerosis. Neurology 1996;46:907-911.

7. Goodman SN. Reviews and commentary: p values, hypothesis tests, and likelihood: implications for epidemiology of a neglected historical debate. Am J Epidemiol 1993:137:485-496.

8. Bellhouse DR. Invited commentary: $p$ values, hypothesis tests, and likelihood. Am J Epidemiol 1993;137:497-499.

9. Goodman SN. Author's response to invited commentary: $p$ values, hypothesis tests, and likelihood. Am J Epidemiol 1993; 137:500-501.

10. Goodin DS. Perils and pitfalls in the interpretation of clinical trials: A reflection on the recent experience in multiple sclerosis. Neuroepidemiology 1999;18:53-63.

11. O'Brien PC. Procedures for comparing samples with multiple endpoints. Biometrics 1984;40:1079-1087.

12. Thomas DC, Siemiatycki J, Dewar R, et al. The problem of multiple inference in studies designed to generate hypotheses. Am J Epidemiol 1985;122:1080-1095.

13. Rothman KJ. Significance questing. Ann Int Med 1986;105: $445-447$.

14. Tandon PK. Applications of global statistics in analyzing quality of life data. Stat Med 1990;9:819-827.

15. Hochberg Y, Benjamini Y. More powerful procedures for multiple significance testing. Stat Med 1990;9:811-818.

16. Cohen J. Statistical power analysis for the behavioral sciences, 2nd ed. Hillsdale, NJ: Lawrence Erlbaum Associates, 1988. 
17. Johnson KP, Brooks BR, Cohen JA, et al. Copolymer 1 reduces relapse rate and improves disability in relapsing-remitting multiple sclerosis: results of a phase III multicenter, doubleblind, placebo-controlled trial. Neurology 1995;45:1268-1276.

18. The IFNB Multiple Sclerosis Study Group. Interferon beta-1b is effective in relapsing-remitting multiple sclerosis: I. clinical results of a multicenter, randomized, double blind, placebocontrolled trial. Neurology 1993;43:655-661.

19. Paty DW, Li DKB, UBC MS/MRI Study Group, IFNB Multiple Sclerosis Study Group. Interferon beta-1b is effective in remitting and relapsing multiple sclerosis: II. MRI analysis results of a multicenter, randomized, double-blind, placebo-controlled trial. Neurology 1993;43:662-667.

20. The IFNB Multiple Sclerosis Study Group and the UBC MS/ MRI Analysis Group. Interferon beta-1b in the treatment of MS: final outcome of the randomized controlled trial. Neurology $1995 ; 45: 1277-1285$.

21. Jacobs LD, Cookfair DL, Rudick RA, et al. Intramuscular interferon beta-1a for disease progression in exacerbatingremitting multiple sclerosis. Ann Neurol 1996;39:285-294.

22. Simon JH, Jacobs LD, Campion M, et al. Magnetic resonance studies of intramuscular interferon $\beta-1$ a for relapsing multiple sclerosis. Ann Neurol 1996;43:79-87.

23. Rudick RA, Goodkin DE, Jacobs LD, et al. Impact of interferon beta-1a on neurologic disability in relapsing multiple sclerosis. The Multiple Sclerosis Collaborative Research Group. Neurology 1997;49:358-363.

24. The Once Weekly Interferon for MS Study Group. Evidence of interferon beta-1a dose response in relapsing-remitting MS: the OWIMS Study. Neurology 1999;53:679-686.

25. Biogen Inc., 1995. Summary basis of approval. FDA official document for license of interferon beta-1a (Avonex), Cambridge, MA. On file at: www.fda.gov/cber/products/ifnbbio051796.htm.

26. PRISMS Study Group. Randomized double-blind placebocontrolled study of interferon $\beta-1 \mathrm{a}$ in relapsing-remitting multiple sclerosis. Lancet 1998;352:1498-1504.

27. Li DK, Paty DW, UBC MS/MRI Analysis Research Group, PRISMS Study Group. Magnetic resonance imaging results of the PRISMS trial: a randomized, double-blind, placebocontrolled study of interferon-beta1a in relapsing-remitting multiple sclerosis. Prevention of relapses and disability by interferon-beta1a subcutaneously in multiple sclerosis. Ann Neurol 1999;46:197-206.

28. Rudick RA, Fisher E, Lee JC, et al. and the Multiple Sclerosis Collaborative Research Group. Use of the brain parenchymal fraction to measure whole brain atrophy in relapsingremitting MS. Neurology 1999;53:1698-1704.

29. European Study Group on Interferon beta-1b in Secondary Progressive MS. Placebo-controlled multicentre randomized trial of interferon $\beta-1 \mathrm{~b}$ in treatment of secondary progressive multiple sclerosis. Lancet 1998;352:1491-1497.

30. Goodkin DE, North American SPMS Study Group. The North American Study of interferon beta-1b in secondary progressive multiple sclerosis. $52^{\text {nd }}$ Annual Meeting of the American Academy of Neurology, San Diego, CA, 2000. Abstract \# LBN.002.

31. SPECTRIMS Study Group. Randomized controlled trial of interferon-beta-1a in secondary progressive MS: clinical results. Neurology 2001;56:1496-1504.

32. Li DKB, Zhao GJ, Paty DW, et al. Randomized controlled trial of interferon-beta-1a in secondary progressive MS: MRI results. Neurology 2001;56:1505-1513.

33. Cohen JA, Goodman AD, Heidenreich FR, et al. Results of IMPACT, a phase 3 trial of interferon beta-1a in secondary progressive MS. Neurology 2001;56(suppl 3):A148-A149.

34. Jacobs LD, Beck RW, Simon JH, et al., CHAMPS Study Group. Intramuscular interferon beta-1a therapy initiated during a first demyelinating event in multiple sclerosis. N Engl J Med 2000;343:898-904.

35. Comi G, Filippi M, Barkhof F, et al. Effect of early interferon treatment on conversion to definite multiple sclerosis: a randomised study. Lancet 2001;357:1576-1582.

36. Stürzebecher S, Maibauer R, Heuner A, Beckmann K, Aufdembrincke B. Pharmacodynamic comparison of single doses of IFNß1a and IFNß1b in healthy volunteers. J Interferon Cytokine Res 1999;19:1257-1264.
37. Borden E, Paulnock D, Spear G, et al. Biological response modification in man: measurement of interferon induced proteins. In: Baron S, Dianzani F, Stanton JC, Fleischman WR, eds. The interferon system: a current review. Austin: University of Texas, 1986;1-7.

38. Deisenhammer F, Mayringer I, Harvey J, et al. A comparative study of the relative bioavailability of different interferon beta reparations. Neurology 2000;54:2055-2060.

39. Alam J, Goelz S, Rioux P, et al. Comparative pharmacokinetics and pharmacodynamics of two recombinant human interferon beta-1a (IFN $\beta$-1a) products administered intramuscularly in healthy male and female volunteers. Pharmaceut Res 1997; 14:546-549.

40. Salmon P, Le Cotonnee JY, Galazka A, Abduhl-Ahad A, Darragh A. Pharmacokinetics and pharmacodynamics of recombinant human interferon-beta in healthy male volunteers. J Interferon Cytokine Res 1996;16:759-764.

41. Munafo A, Trinchard-Lugan I, Nguyen TXQ, Buraglio M. Comparative pharmicokinetics and pharmicodynamics of recombinant human interferon beta-1a after intramuscular and subcutaneous administration. Eur J Neurol 1998;5:1-7.

42. PRISMS Study Group. PRISMS-4: long-term efficacy of interferon- $\beta-1 \mathrm{a}$ in relapsing MS. Neurology 2001;56:16281636.

43. Clanet M, Kappos L, Radue EW, et al. Results of the European interferon beta-1a (Avonex) dose-comparison study. J Neurol 2001;248(suppl 2):II/63.

44. Durelli L, Ferrero T, Ghezzi G, et al. The independent comparison of interferon (INCOMIN) trial: a multicenter randomized trial comparing clinical and MRI efficacy of IFN btea-1a and beta-1b in multiple sclerosis. Neurology 2001;56(suppl 3):A148.

45. Coyle P. Results of comparative efficacy trial using two formulations of interferon beta-1a in RRMS. J Neurol Sci 2001; 187(suppl 1):S436.

46. Teitelbaum D, Aharoni R, Sela M, Arnon R. Cross-reactions and specificities of monoclonal antibodies against myelin basic protein and against the synthetic copolymer-1. Proc Natl Acad Sci USA 1991;88:9528-9532.

47. Teitelbaum D, Milo R, Arnon R, Sela M. Synthetic copolymer-1 inhibits human T-cell lines specific for myelin basic protein. Proc Natl Acad Sci USA 1992;89:137-141.

48. Neuhaus O, Farina C, Wekerle H, Hohlfeld R. Mechanisms of action of glatiramer acetate in multiple sclerosis. Neurology 2001;56:702-708.

49. Johnson KP, Brooks BR, Cohen JA, et al. Extended use of glatiramer acetate (Copaxone) is well tolerated and maintains its clinical effect on multiple sclerosis relapse rate and degree of disability. Neurology 1998;50:701-708.

50. Comi G, Filippi M, Wolinsky JS, et al. European/Canadian multicenter, double-blind, randomized, placebo-controlled study of the effects of glatiramer acetate on magnetic resonance imaging-measured disease activity and burden in patients with relapsing multiple sclerosis. Ann Neurol 2001;49: 290-297.

51. Bornstein MB, Miller A, Slagle S, et al. A pilot trial of COP 1 in exacerbating-remitting multiple sclerosis N Engl J Med 1987;317:408-414.

52. Bornstein MB, Miller A, Slagle S, et al. A placebo-controlled, double-blind, randomized, two-center, pilot trial of COP 1 in chronic progressive multiple sclerosis. Neurology 1991;41: 533-539.

53. Johnson KP, Brooks BR, Ford CC, et al., and the Copolymer 1 Multiple Sclerosis Study Group. Sustained clinical benefits of glatiramer acetate in relapsing multiple sclerosis patients observed for 6 years. Mult Scler 2000;6:255-266.

54. Wolinsky JS, Narayana PA, Johnson KP, et al. United States open-label glatiramer acetate extension trial for relapsing multiple sclerosis: MRI and clinical correlates. Mult Scler $2001 ; 7: 33-41$

55. Khan OA, Tselis AC, Kamholz JA, et al. A prospective, openlabel treatment trial to compare the effect of IFN beta-1a (Avonex), IFN beta-1b (Betaseron), and glatiramer acetate (Copaxone) on the relapse rate in relapsing-remitting multiple sclerosis. Eur J Neurol 2001;8:141-148. 


\section{Neurology}

\section{Disease modifying therapies in multiple sclerosis: Subcommittee of the American}

Academy of Neurology and the MS Council for Clinical Practice Guidelines

Report of the Therapeutics and Technology Assessment Subcommittee of the American Academy of Neurology and the MS Council for Clinical Practice Guidelines, D. S. Goodin,

E. M. Frohman, et al.

Neurology 2002;58;169-178

DOI 10.1212/WNL.58.2.169

This information is current as of January 22, 2002

\section{Updated Information \& \\ Services}

Supplementary Material

References

Citations

Permissions \& Licensing

Reprints including high resolution figures, can be found at: http://n.neurology.org/content/58/2/169.full

Supplementary material can be found at: http://n.neurology.org/content/supp1/2002/02/01/58.2.169.DC3

This article cites 42 articles, 16 of which you can access for free at: http://n.neurology.org/content/58/2/169.full\#ref-list-1

This article has been cited by 45 HighWire-hosted articles: http://n.neurology.org/content/58/2/169.full\#\#otherarticles

Information about reproducing this article in parts (figures,tables) or in its entirety can be found online at:

http://www.neurology.org/about/about_the_journal\#permissions

Information about ordering reprints can be found online:

http://n.neurology.org/subscribers/advertise

Neurology ${ }^{\circledR}$ is the official journal of the American Academy of Neurology. Published continuously since 1951, it is now a weekly with 48 issues per year. Copyright . All rights reserved. Print ISSN: 0028-3878.

Online ISSN: 1526-632X.

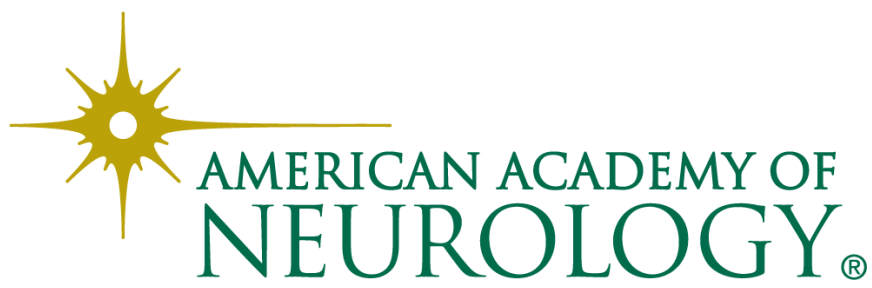

